\title{
Enantiopure ethyl 2,3-dibromopropionate: Enantioselective synthesis vs preparative HPLC enantioseparation of racemate on multigram scale
}

\author{
Hong-Ngoc Pham ${ }^{1,2}$ | Axelle Arrault ${ }^{1}$ (i) | Nicolas Vanthuyne ${ }^{3}$ (i) | \\ Samir Acherar ${ }^{1}$ (이
}

\begin{abstract}
Racemic ethyl 2,3-dibromopropionate, commercially available at low price, is a key intermediate used in the synthesis of several heterocycle fragments, which are present in many biologically active compounds. Surprisingly, the enantiomers are not commercially available and have never been described in the literature. In this work, we undertook two different strategies to obtain these enantiomers, which are enantioselective synthesis and preparative HPLC enantioseparation of commercially available racemate on multigram scale. The first strategy has proved inadequate because racemization occurred during the synthesis (ee $\approx 9-50 \%$ ). Conversely, the second strategy produced a very good enantioseparation of commercially available racemate (ee $>99.5 \%$ for both enantiomers) on multigram scale.
\end{abstract}

\section{KE Y W O R D S}

chiral stationary phases, enantioselective chromatography, ethyl 2,3-dibromopropionate, preparative resolution, racemization

\section{1 | INTRODUCTION}

As pharmacological activity depends on threedimensional drug-receptor interactions, the enantiomers of chiral drugs may differ widely in biological activity. As the result, the term "chirality" becomes a crucial issue for drug design, which implies that most of synthesized and marketed drugs today are in enantiopure forms. ${ }^{1}$ There are several and different proficient ways to obtain an enantiopure product ${ }^{2}$ : enantioselective synthesis, from chiral pool or from prochiral substrates, and separation of racemic mixtures by crystallization of enantiomers or diastereomers, ${ }^{3}$ kinetic resolution, ${ }^{4}$ or chromatography on chiral stationary phases (CSPs). ${ }^{5-9}$

The ethyl 2,3-dibromopropionate racemate rac-2 (Scheme 1) is an interesting key intermediate used in various heterocycle synthesis in the literature. Among these heterocycles, we could mention aziridine2-carboxylates, ${ }^{10}$ 2-hydroxymethyl-1,4-benzodioxans, ${ }^{11}$ and 1,4-benzoxazine-2-carboxylates. ${ }^{12,13}$ Some of these heterocycle compounds display interesting biological activities with antihepatotoxic, ${ }^{14}$ anti-angiogenesis, ${ }^{15,16}$ anti-bacterial, ${ }^{17}$ antihypertensive, ${ }^{18,19}$ or neuroprotective $^{20}$ effects. However, despite this overwhelming interest, only rac-2 is commercially available at low price and optically pure enantiomers $(S)-2$ and $(R)-2$ have never been described in the literature. Interestingly, the corresponding chiral carboxylic acid and other related chiral esters, from which the enantiomers of $\mathbf{2}$ could be obtained easily, have also never been described.

In view of these observations, the goal of this work is to investigate two different strategies to obtain these enantiomers, which are enantioselective synthesis of (S)-2 and preparative HPLC enantioseparation of 
commercially available rac-2 on multigram scale. This work shows that preparative HPLC enantioseparation is the best method for obtaining these enantiomers with high enantiomeric excess (ee $>99.5 \%$ ) because racemization occurred during the synthesis (ee $\approx 9-50 \%$ ).

\section{2 | MATERIALS AND METHODS}

\section{1 | Chemicals}

Unless otherwise stated, all chemicals were purchased from Sigma-Aldrich as the highest purity commercially available and were used without further purification. Dry $\mathrm{CH}_{2} \mathrm{Cl}_{2}$ was obtained by distillation over $\mathrm{P}_{2} \mathrm{O}_{5}$ under an argon atmosphere, and other reagent-grade solvents were used as received. Ethyl 2,3-dibromopropionate racemate rac-2 ( $\geq 98 \%, 259.92 \mathrm{~g} / \mathrm{mol})$ was purchased from SigmaAldrich. Ethanol, hexane, and heptane were HPLC grade and were purchased from VWR.

\section{2 | Characterization}

Reactions were monitored by thin-layer chromatography (TLC) using aluminum-backed silica gel plates (Macherey-Nagel ALUGRAM ${ }^{\circledR}$ SIL G/UV254). TLC spots were viewed under ultraviolet light or/and by heating the plate after treatment with a staining solution of phosphomolybdic acid or ninhydrin. Product purifications were performed using Geduran $60 \mathrm{H}$ Silica Gel (63-200 mesh). NMR spectra were recorded on a Brucker Advance 300 spectrophotometer in $\mathrm{CDCl}_{3}$ solvent at $298 \mathrm{~K}$. Tetramethylsilane (TMS, $\delta=0 \mathrm{ppm}$ ) and $\mathrm{CDCl}_{3}$ $(\delta=77.0 \mathrm{ppm})$ residual peaks were used as internal references for ${ }^{1} \mathrm{H}$ and ${ }^{13} \mathrm{C}$ NMR, respectively. Chemical shift $(\delta)$ were reported in parts per million ( $\mathrm{ppm})$, and coupling constants $(J)$ were given in hertz $(\mathrm{Hz})$. Multiplicity was defined as $\mathrm{s}$ for singlet, $\mathrm{d}$ for doublet, $\mathrm{t}$ for triplet, q for quadruplet, $\mathrm{m}$ for multiplet, br for broad, or combinations thereof. Electrospray mass spectroscopy (ESI-MS) was performed on a ToF-Q HR spectrometer. HRMS spectra were obtained by the ESI method.

\section{3 | Synthesis of $(S)$-ethyl 2,3-dibromopropionate, $(S)$-2 (methods A-C)}

Ethyl glycerate $(S)-\mathbf{1}\left([\alpha]_{\mathrm{D}}{ }^{25}=-11.2\left(\mathrm{CHCl}_{3}, c=1.00\right)\right)$, lit. $^{21}\left([\alpha]_{\mathrm{D}}{ }^{23}=-11.6\left(\mathrm{CHCl}_{3}, c=1.00\right)\right)$ was prepared in $70 \%$ overall yield from $(S)$-serine in two steps following the procedure previously described by Mukaiyama et al...

\subsection{1 | Method A}

$N$-bromosuccinimide ( 1 or 3 equiv.) and $\mathrm{PPh}_{3}$ ( 1 or 3 equiv.) were added successively to a solution of $(S)-\mathbf{1}$ (200 mg, $1.5 \mathrm{mmol}, 1$ equiv.) in $\mathrm{CH}_{2} \mathrm{Cl}_{2}$ or $\mathrm{Et}_{2} \mathrm{O}(10 \mathrm{~mL}$ ) by portions at $0{ }^{\circ} \mathrm{C}$. The mixture was stirred for 3 hours at $0{ }^{\circ} \mathrm{C}$ and then for 3 to 9 hours at room temperature. The reaction mixture was concentrated in vacuo, and the resulting crude material was purified by flash chromatography (hexane/EtOAc, 30/70, v/v) to afford only the starting material $(S)-\mathbf{1}(80 \%)$.

\subsection{2 | Method B}

Pyridine (1.1 equiv.) was added to a solution of $(S)-\mathbf{1}$ (200 mg, 1.5 mmol, 1 equiv.) in $\mathrm{CH}_{2} \mathrm{Cl}_{2}$ or $\mathrm{Et}_{2} \mathrm{O}$ $(10 \mathrm{~mL})$ at $-10^{\circ} \mathrm{C}$. After 15 minutes of stirring, $\mathrm{PBr}_{3}$ ( 1,3 or 5 equiv.) was added dropwise at $-10{ }^{\circ} \mathrm{C}$ and the resulting mixture was stirred at room temperature for 2 to 24 hours. The reaction mixture was poured over ice and extracted with $\mathrm{CH}_{2} \mathrm{Cl}_{2}$ or $\mathrm{Et}_{2} \mathrm{O}$ $(3 \times 20 \mathrm{~mL})$. The organic phases were combined and washed with saturated $\mathrm{NaHCO}_{3}(10 \mathrm{~mL})$ and brine $(10 \mathrm{~mL})$, dried over $\mathrm{MgSO}_{4}$, and concentrated. The reaction mixture was concentrated in vacuo, and the resulting crude material was purified by flash chromatography (hexane/EtOAc, 30/70, v/v) to afford only the starting material $(S)-\mathbf{1}(70 \%)$.

\subsection{3 | Method C}

$\mathrm{PPh}_{3}$ (2 or 3 equiv.) was added to a solution of $(S)-\mathbf{1}$ (200 mg, $1.5 \mathrm{mmol}, 1$ equiv.) in $\mathrm{CH}_{2} \mathrm{Cl}_{2}(10 \mathrm{~mL})$ at $0{ }^{\circ} \mathrm{C}$. After 20 to 30 minutes of stirring, $\mathrm{CBr}_{4}$ (2 or 3 equiv.) was added dropwise at $0{ }^{\circ} \mathrm{C}$ and the resulting mixture was stirred at room temperature for either $8,11,14,17$, or 20 hours. The reaction mixture was concentrated in vacuo, and the resulting crude material was purified by flash chromatography (petroleum ether/EtOAc, 90/10, v/v) to afford the dibromo compound $(S)-2$ in 24 to $82 \%$ yield as yellow oil (ee $\approx 9-50 \%) .{ }^{1} \mathrm{H}$ NMR $\left(300 \mathrm{MHz}, \mathrm{CDCl}_{3}\right) \delta 1.32(\mathrm{t}, 3 \mathrm{H}$, $\left.J=6.9 \mathrm{~Hz}, \mathrm{CH}_{3}\right), 3.67(\mathrm{dd}, 1 \mathrm{H}, J=4.5$ and $9.9 \mathrm{~Hz}$, $\mathrm{CH}_{2}-\mathrm{Br}$ ), 3.92 (dd, $1 \mathrm{H}, J=9.9$ and $11.1 \mathrm{~Hz}, \mathrm{CH}_{2}-\mathrm{Br}$ ), 4.29 (q, $\left.2 \mathrm{H}, J=6.9 \mathrm{~Hz}, \mathrm{OCH}_{2}\right), 4.42(\mathrm{dd}, 1 \mathrm{H}, \mathrm{J}=4.5$ and $11.1 \mathrm{~Hz}, \mathrm{CH}-\mathrm{Br}) ;{ }^{13} \mathrm{C}$ NMR $\left(75 \mathrm{MHz}, \mathrm{CDCl}_{3}\right.$ ) $\delta 14.56\left(\mathrm{CH}_{3}\right), 30.37\left(\mathrm{CH}_{2}-\mathrm{Br}\right), 41.84(\mathrm{CH}-\mathrm{Br}), 63.24$ $\left(\mathrm{OCH}_{2}\right), 168.16(\mathrm{C}=\mathrm{O})$; HRMS (ESI) calculated for $\mathrm{C}_{5} \mathrm{H}_{8} \mathrm{Br}_{2} \mathrm{O}_{2}[\mathrm{M}+\mathrm{Na}]^{+} \mathrm{m} / \mathrm{z} 280.8788$, found 280.8783 (see Supporting Information, Appendix A for a copy of 1D and 2D NMR spectra). 


\subsection{Enantioselective HPLC}

Analytical and preparative HPLC experiments were performed on an Agilent 1260 Infinity unit (pump G1311B, autosampler G1329B, DAD G1315D), with Jasco CD-1595 circular dichroism detector. The analytical $(250 \times 4.6 \mathrm{~nm})$ and preparative columns were purchased from Chiral Technologies Europe (Illkirch, France), Phenomenex (Le Pecq, France), or Regis Technologies (Morton Grove, USA) (see Supporting Information, Appendix B for more details). HPLC grade heptane, hexane, and ethanol were degassed and filtered on a 45- $\mu \mathrm{m}$ Millipore membrane before use. Retention times $\mathrm{Rt}$ in minutes, retention factors $k_{i}=\left(\mathrm{Rt}_{\mathrm{i}}-\mathrm{Rt}_{0}\right) / \mathrm{Rt}_{0}$, and enantioselectivity factor $\alpha=k_{2} / k_{1}$ and resolution $\mathrm{Rs}=1.18$ $\left(\mathrm{Rt}_{2}-\mathrm{Rt}_{1}\right) /\left(w_{1}+w_{2}\right)$ are given. $\mathrm{Rt}_{0}$ was determined by injection of 1,3,5-tri-tert-butylbenzene, and $w_{\mathrm{i}}$ was the peak width at half-height.

\subsection{1 | Analytical HPLC}

About $20 \mu \mathrm{L}$ of a $3 \mathrm{mg} / \mathrm{mL}$ solution in ethanol was injected on the chiral column and detected with an UV and circular dichroism detectors at $254 \mathrm{~nm}$. A mixture of heptane/EtOH (98/2 or 95/5, v/v) as mobile phase with a flow-rate of $1 \mathrm{~mL} / \mathrm{min}$ was used.

\subsection{2 | Preparative HPLC}

The preparative HPLC on multigram scale was performed starting from a solution of around $5 \mathrm{~g}$ of commercially available racemate $(R, S)$-ethyl 2,3-dibromopropionate (rac-2) in $60 \mathrm{~mL}$ of the mobile phase (hexane/EtOH, 95/5, v/v). Every 1.2 minutes, $50 \mu \mathrm{L}$ of this solution (1200 injections) was injected (stacked method) in the preparative Chiralpak AD-H $(250 \times 10 \mathrm{~mm}, 5 \mu \mathrm{m})$ column using a flowrate of $5 \mathrm{~mL} / \mathrm{min}$ and UV (254 nm) detection. Both enantiomers were separated and collected in two fractions of around $2.3 \mathrm{~g}$ with high purity (ee > 99.5\%) (see Supporting Information, Appendix $\mathrm{C}$ for more detail about preparative HPLC enantioseparation of rac-2).

\section{5 | Chiroptical characterization}

\subsection{1 | Optical rotation measurements}

Optical rotations of both enantiomers $\left(\mathrm{CH}_{2} \mathrm{Cl}_{2}, c=3.2\right)$ were measured on a JASCO P-2000 polarimeter with a sodium lamp $(\lambda=589 \mathrm{~nm})$ or a halogen lamp $(\lambda=578$,
546, 436, and $405 \mathrm{~nm}$ ) in a $10-\mathrm{cm}$ cell thermostated at $25^{\circ} \mathrm{C}$ with a Peltier controlled cell holder.

\subsection{2 | ECD and UV spectra}

ECD and UV spectra of both enantiomers in acetonitrile $(c=7.2 \mathrm{mM})$ were measured on a JASCO J-815 spectrometer equipped with a JASCO Peltier cell holder PTC-423 to maintain the temperature at $25.0 \pm 0.2{ }^{\circ} \mathrm{C}$. A CD quartz cell of $1 \mathrm{~mm}$ of optical pathlength was used. The CD spectrometer was purged with nitrogen before recording each spectrum, which was baseline subtracted. The baseline was always measured for the same solvent and in the same cell as the samples. The spectra are presented without smoothing and further data processing. About $0.1 \mathrm{~nm}$ as intervals, scanning speed $50 \mathrm{~nm} / \mathrm{min}$, band width $2 \mathrm{~nm}$, and 3 accumulations per sample were used as acquisition parameters.

\section{3 | RESULTS AND DISCUSSION}

\section{1 | Enantioselective synthesis of $(S)$ - ethyl 2,3-dibromopropionate}

Our strategy to synthesize $(S)-\mathbf{2}$ is based on bromination reactions starting from enantiomerically pure ethyl glycerate $(S)-\mathbf{1}\left([\alpha]_{\mathrm{D}}{ }^{25}=-11.2\left(\mathrm{CHCl}_{3}, c=1.00\right)\right.$, lit. ${ }^{21}$ $\left([\alpha]_{\mathrm{D}}^{23}=-11.6\left(\mathrm{CHCl}_{3}, c=1.00\right)\right)$ as described in Scheme 1. $(S)-\mathbf{1}$ is prepared in $70 \%$ overall yield from $(S)$-serine in two steps following the several days procedure previously described by Mukaiyama et al. ${ }^{22}$ and subjected to a double bromination reaction with $N$-bromosuccinimide (NBS, Method A), phosphorus tribromide $\left(\mathrm{PBr}_{3}\right.$, Method $\left.\mathrm{B}\right)$, or carbon tetrabromide $\left(\mathrm{CBr}_{4}\right.$, Method C) as brominating agents and triphenylphosphine $\left(\mathrm{PPh}_{3}\right.$, Methods $\mathrm{A}$ and $\left.\mathrm{C}\right)$ or pyridine (Method B) as co-reagents in $\mathrm{CH}_{2} \mathrm{Cl}_{2}$ or $\mathrm{Et}_{2} \mathrm{O}$ as solvents (Scheme 1). The starting material $(S)-\mathbf{1}$ is always recovered with no racemization by using Methods A and B (Scheme 1). Despite several attempts, only Method C (Appel reaction) with 2 or 3 equivalents of $\mathrm{CBr}_{4}$ and $\mathrm{PPh}_{3}$ provides (S)-2 with yields from 24 to $82 \%$ (Scheme 1). It is also interesting to note that the Method $\mathrm{C}$ does not work with 1 equivalent of $\mathrm{CBr}_{4}$ and $\mathrm{PPh}_{3}$. The Appel reaction in Method $\mathrm{C}$ proceeds via an $\mathrm{S}_{\mathrm{N}} 2$ mechanism with spatial inversion of stereochemistry and affords $(S)-2$.

To ensure the effectiveness of this strategy in obtaining enantiomerically pure $(S)-2$, optical purity determination of $(S)-2$ is crucial. For this reason, analytical chiral HPLC separation of commercially available racemate rac- 2 is investigated in order to be able to 


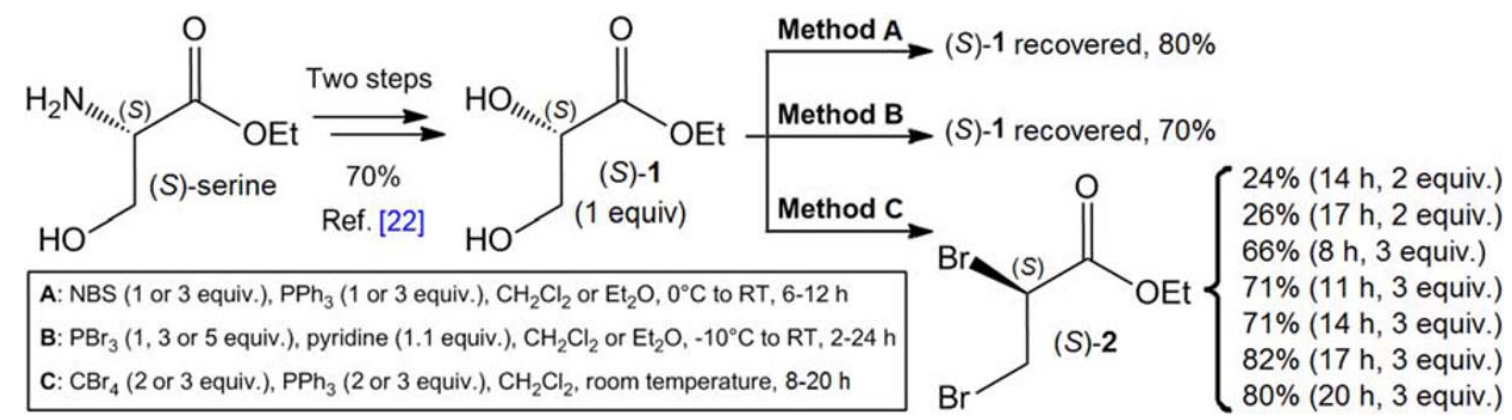

SCHEME 1 Enantioselective synthesis of $(S)-2$

determine the ee value of the synthesized (S)-2. To obtain complete resolution of the racemate $\mathbf{r a c}-2$, a screening of 14 different CSPs $(250 \times 4.6 \mathrm{~mm})$ is undertaken using a mixture of heptane/EtOH (98/2 or 95/5, v/v) as mobile phase with a flow-rate of $1 \mathrm{~mL} / \mathrm{min}$ under UV and circular dichroism $(254 \mathrm{~nm})$ detection. The chromatographic results of the screening are reported in Table 1 (see Supporting Information, Appendix B for HPLC chromatograms). Experimental data indicate that no separation $(\alpha=1$, entries $1,3,4,6,9,10,12$, and 14; Table 1) or no baseline separation (Rs < 1.5; entries 2, 11, and 13, Table 1) is obtained for the majority of CSPs. Baseline separation is observed on Chiralpak AZ-H, Chiralpak IA, and Lux-Amylose- ${ }^{\circledR}$ (entries 5, 7, and 8 , Table 1), but only Lux-Amylose-1 ${ }^{\circledR}$ CSP shows a good resolution for $\boldsymbol{r a c}-2$ (Rs > 3; entries $5 \mathrm{a}$ and $5 \mathrm{~b}$, Table 1 and Figure 1A,B). HPLC chromatogram using Lux-Amylose- $1^{\circledR}$ as CSP and heptane/EtOH (95/5, v/v) as mobile phase (entry $5 \mathrm{~b}$, Table 1 ) gives retention times of 4.74 and 5.21 minutes for (-)-2 and (+)-2 enantiomers, respectively, with a Rs value of 3.13 (Figure 1A,B). The circular dichroism detector reveals that the elution order is $(-)_{\mathrm{CD} 254 \mathrm{~nm}} /(+)_{\mathrm{CD} 254 \mathrm{~nm}}$ on amylose-based CSPs, whereas the $(+)_{\mathrm{CD} 254 \mathrm{~nm}}$ is the first eluted on the only cellulose based CSP (Chiralcel OD-3). The resolution is worse on immobilized polysaccharide CSPs (Chiralpak IA and IF) than on the corresponding coated CSPs (Lux-Amylose- $1^{\circledR}$ and Chiralpak AZ-H).

Finally, the various ee of the synthesized $(S)-2$ from Method $\mathrm{C}$ are determined by the analytical HPLC

T A B LE 1 Screening results for analytical HPLC enantioseparation of rac-2

\begin{tabular}{|c|c|c|c|c|c|c|c|c|}
\hline \multirow[b]{2}{*}{ Entry } & \multirow[b]{2}{*}{ Column } & \multirow[b]{2}{*}{ Heptane/EtOH (v/v) } & \multicolumn{2}{|c|}{ First Eluted Enantiomer } & \multicolumn{2}{|c|}{ Second Eluted Enantiomer } & \multirow{2}{*}{$\alpha^{\alpha^{c}}$} & \multirow{2}{*}{$\mathbf{R s}^{\mathbf{d}}$} \\
\hline & & & $\mathbf{R t}_{\mathbf{1}}{ }^{\mathbf{a}}$ & $k_{1}^{b}$ & $\mathbf{R t}_{2}{ }^{\mathbf{a}}$ & $k_{2}^{b}$ & & \\
\hline 1 & Chiralpak AS-H & $98 / 2$ & 4.08 & 0.38 & - & - & 1 & 0 \\
\hline 2 & Chiralcel OD-3 & $98 / 2$ & $4.46(+)$ & 0.51 & $4.57(-)$ & 0.55 & 1.07 & 0.52 \\
\hline 3 & Lux-Cellulose-2 & $98 / 2$ & 4.22 & 0.43 & - & - & 1 & 0 \\
\hline 4 & Lux-Cellulose-4 & $98 / 2$ & 4.10 & 0.39 & - & - & 1 & 0 \\
\hline $5 \mathrm{a}$ & Lux-Amylose-1 & $98 / 2$ & $5.13(-)$ & 0.74 & $5.76(+)$ & 0.95 & 1.29 & 3.68 \\
\hline $5 b$ & Lux-Amylose-1 & $95 / 5$ & $4.74(-)$ & 0.61 & $5.21(+)$ & 0.77 & 1.26 & 3.13 \\
\hline 6 & Lux-Amylose-2 & $98 / 2$ & 5.04 & 0.71 & - & - & 1 & 0 \\
\hline 7 & Chiralpak AZ-H & $98 / 2$ & $5.38(-)$ & 0.82 & $5.64(+)$ & 0.91 & 1.11 & 1.28 \\
\hline 8 & Chiralpak IA & $98 / 2$ & $4.84(-)$ & 0.64 & $5.19(+)$ & 0.76 & 1.18 & 1.40 \\
\hline 9 & Chiralpak IB & $98 / 2$ & 4.20 & 0.42 & - & - & 1 & 0 \\
\hline 10 & Chiralpak IC & $98 / 2$ & 4.32 & 0.46 & - & - & 1 & 0 \\
\hline 11 & Chiralpak ID & $98 / 2$ & $4.87(-)$ & 0.65 & $5.09(+)$ & 0.73 & 1.12 & 0.76 \\
\hline 12 & Chiralpak IE & $98 / 2$ & 5.10 & 0.73 & - & - & 1 & 0 \\
\hline 13 & Chiralpak IF & $98 / 2$ & $5.38(-)$ & 0.82 & $5.63(+)$ & 0.91 & 1.10 & 1.04 \\
\hline 14 & $(S, S)$-Whelk-O1 & $98 / 2$ & 4.72 & 0.60 & - & - & 1 & 0 \\
\hline
\end{tabular}

${ }^{\mathrm{a}}$ Retention time ( $\left.\mathrm{min}\right)$.

${ }^{\mathrm{b}}$ Retention factor.

'Enantioselectivity factor.

${ }^{\mathrm{d}}$ Resolution. 
(A)

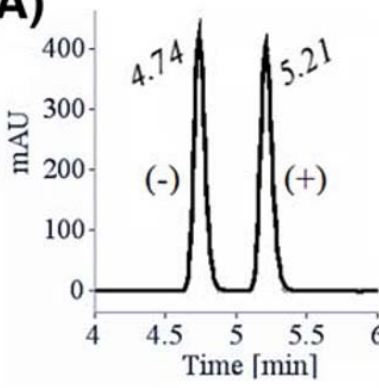

(C)
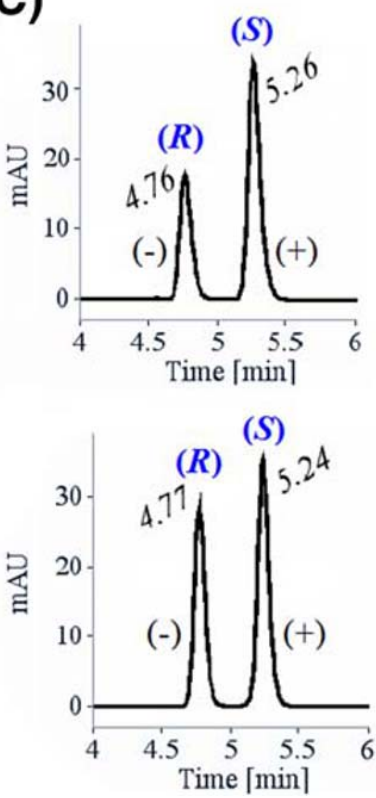

\begin{tabular}{|c|c|c|c|c|c|}
\cline { 2 - 6 } \multicolumn{1}{c|}{} & \multicolumn{4}{c|}{ Commercially available rac-2 } \\
\hline $\begin{array}{c}\text { CD } \\
\mathbf{2 5 m})\end{array}$ & $\mathbf{R t}(\mathbf{m i n})$ & Area\% & $\mathbf{k}$ & $\boldsymbol{\alpha}$ & $\mathbf{R s}$ \\
\hline$(-)$ & 4.74 & 50.01 & 0.61 & \multirow{2}{*}{1.26} & 3.13 \\
\hline $\mathbf{( + )}$ & 5.21 & 49.99 & 0.77 & & \\
\hline
\end{tabular}

(B)

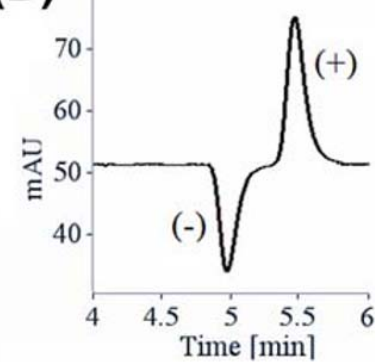

(D)
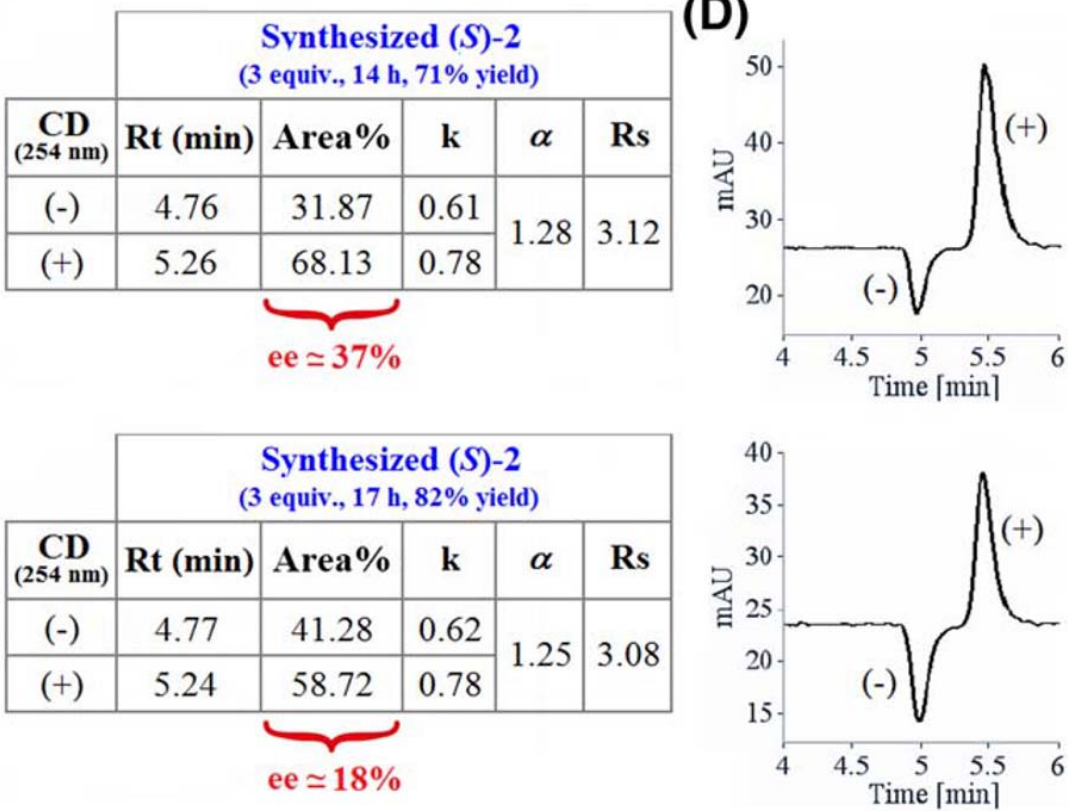

F I G U RE 1 Analytical HPLC enantioseparation of commercially available rac-2 (A,B) and two examples of the synthesized (S)-2 (C,D) using Lux-Amylose- ${ }^{\circledR}$ as CSP and heptane/EtOH (95/5, v/v) as mobile phase under (A,C) UV and (B,D) circular dichroism (254 nm) detection

system using Lux-Amylose- $1^{\circledR} \quad$ as $\quad$ CSP and heptane/EtOH $(95 / 5, \mathrm{v} / \mathrm{v})$ as mobile phase, leading to ee values from $\approx 9$ to $50 \%$ (Figure $1 \mathrm{C}, \mathrm{D}$ and Table 2 ).

T A B L E 2 Ee measurement of the synthesized $(S)-2^{\mathrm{a}}($ Method C)

\begin{tabular}{lllll} 
Entry & $\begin{array}{l}\mathbf{C B r}_{\mathbf{4}} / \mathbf{P P h}_{\mathbf{3}} \\
\text { (equiv.) }\end{array}$ & $\begin{array}{l}\text { Time } \\
\text { (h) }\end{array}$ & $\begin{array}{l}\text { Yield } \\
\mathbf{( \% )}\end{array}$ & $\begin{array}{l}\mathbf{E e} \\
\mathbf{( \% )}\end{array}$ \\
\hline 1 & 2 & 14 & 24 & 49.3 \\
\hline 2 & 2 & 17 & 26 & 35.4 \\
\hline 3 & 3 & 8 & 66 & 33.2 \\
\hline 4 & 3 & 11 & 71 & 29.5 \\
\hline 5 & 3 & 14 & 71 & 36.3 \\
\hline 6 & 3 & 17 & 82 & 17.4 \\
\hline 7 & 3 & 20 & 80 & 8.8 \\
\hline
\end{tabular}

a Using Lux-Amylose- ${ }^{\circledR}$ as CSP and heptane/EtOH (95/5, v/v) as mobile phase under UV and circular dichroism $(254 \mathrm{~nm})$ detection. Abbreviation: CSP: chiral stationary phase.
These low ee for the synthesized $(S)-\mathbf{2}$ show that a racemization process is carried out during the Appel reaction (Method $\mathrm{C}$ ). Table 2 reveals that the racemization process (i) occurs quickly (ee $\approx 33 \%$ with a reaction time of 8 hours, entry 3), (ii) increases with time (comparison of entries $1 / 2$ or $3 / 4 / 5 / 6 / 7$ ), and (iii) proceeds more slowly when fewer equivalents of $\mathrm{CBr}_{4}$ and $\mathrm{PPh}_{3}$ are used (comparison of entries $1 / 5$ or 2/6). Our difficulties in precipitating of soluble phosphine oxide by-product and its presence during the purification process might explain the problem of racemization in the Appel reaction (Method C). ${ }^{23-25}$

\section{2 | Preparative HPLC enantioseparation of commercially available racemate ethyl 2,3-dibromopropionate, rac-2}

Based on the optimized chiral HPLC analytical conditions for commercially available rac-2 mentioned above 
(A)

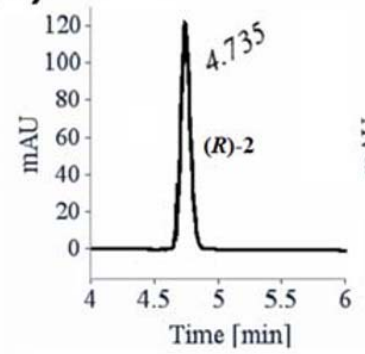

(C)

\begin{tabular}{ccc}
\hline$\lambda(\mathrm{nm})$ & $\begin{array}{c}\text { First fraction }(R)-2 \\
{[\alpha]_{2}^{25}\left(\mathrm{CH}_{2} \mathrm{Cl}_{2}, \mathrm{c}=3,29\right)}\end{array}$ & $\begin{array}{c}\text { Second fraction }(S)-2 \\
{[\alpha]_{2}^{25}\left(\mathrm{CH}_{2} \mathrm{Cl}_{2}, \mathrm{c}=\mathbf{3 , 1 3}\right)}\end{array}$ \\
\hline 589 & +12 & -12 \\
578 & +13 & -13 \\
546 & +14 & -14 \\
436 & +20 & -20 \\
405 & +22 & -22 \\
365 & +22 & -22 \\
\hline
\end{tabular}

(B)

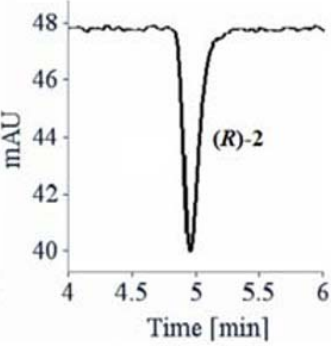

Second fraction $(\mathrm{ee}>\mathbf{9 9 . 5 \%}$ )
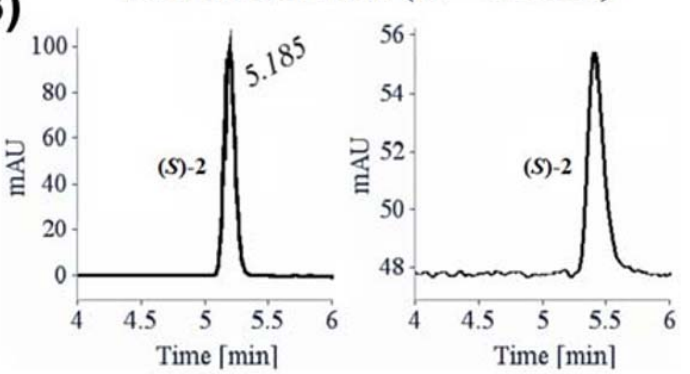

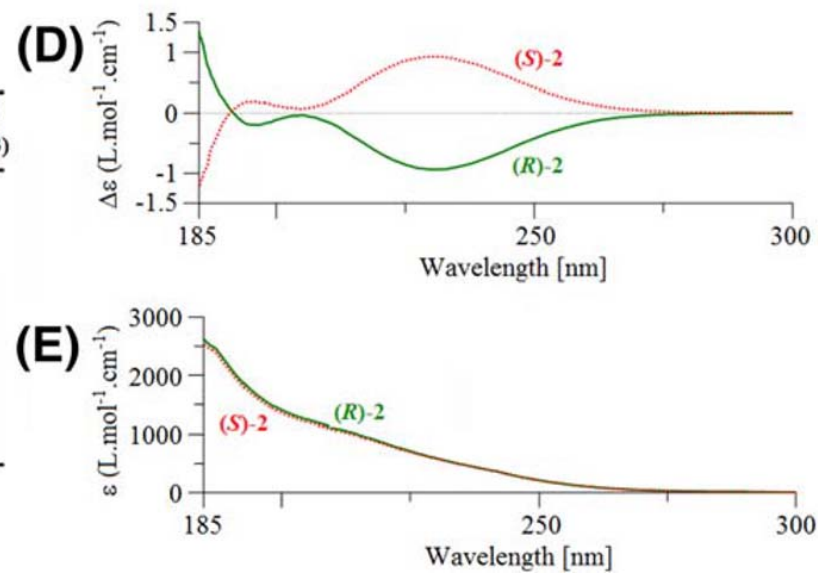

F I G U RE 2 (A,B) HPLC chromatograms of the separated enantiomers from rac-2 and their characterizations by (C) optical rotation measurements $\left(\mathrm{CH}_{2} \mathrm{Cl}_{2}, c=3.2\right)$, (D) ECD and (E) UV spectra (acetonitrile, $c=7.2 \mathrm{mM}$ )

(entry 5b, Table 1), the preparative HPLC enantioseparation of rac-2 on multigram scale is achieved using a preparative Chiralpak $\mathrm{AD}-\mathrm{H}$ chiral column $(250 \times 10 \mathrm{~mm}, 5 \mu \mathrm{m})$. It is worth noting that the analytical Lux-Amylose- $1^{\circledR}$ and preparative Chiralpak AD-H column share the same amylose-based chiral selector (i.e., amylose tris(3,5-dimethyl-phenylcarbamate) coated on silica). The preparative resolution of rac-2 (5 g scale) is successively performed with hexane/EtOH (95/5, $\mathrm{v} / \mathrm{v}, 6 \mathrm{~L}$ ) as mobile phase with a flow-rate of $5 \mathrm{~mL} / \mathrm{min}$ under UV (220 nm) and circular dichroism (254 nm) detection after 1 day injection. A stacked injection technique is used (see Supporting Information, Appendix $\mathrm{C}$ for more detail about preparative HPLC enantioseparation of rac-2). The first $(2.3 \mathrm{~g})$ and the second $(2.3 \mathrm{~g})$ fractions at a retention time of 4.73 and 5.18 minutes, respectively, are isolated with ee higher than $99.5 \%$ (Figure 2A,B). The separated enantiomers are characterized by optical rotation and electronic circular dichroism (ECD) and UV, which show opposite values in optical rotation and ECD spectra (Figure 2C,D), and same UV spectra (Figure 2E). The assignment of the absolute configuration is established for the second fraction, thanks to the HPLC chromatogram of the synthesized $(S)-2$ (ee $\approx 9-50 \%$; Figure 1C,D and Table 2): (S)-2 has a positive ECD band between 200 and $275 \mathrm{~nm}$ (Figure 2D), and a specific rotation $[\alpha]_{\mathrm{D}}{ }^{25}[\alpha]_{D}^{25}=-12$ $\left(\mathrm{CH}_{2} \mathrm{Cl}_{2}, c=3.13\right)$ (Figure $2 \mathrm{C}$ ).

\section{4 | CONCLUSIONS}

In this work, two different strategies to obtain both optically pure enantiomers of ethyl 2,3-dibromopropionate were investigated using enantioselective synthesis or preparative HPLC enantioseparation of commercially available racemate on multigram scale. The enantioselective synthesis of the $S$-enantiomer was efficiently achieved in 3 steps from $(S)$-serine with $58 \%$ overall yield. Unfortunately, analytical chiral HPLC analysis of the synthesized $S$-enantiomer indicated a low ee $(\approx 9-50 \%)$ caused by a racemization process during the bromination step. A possible explanation for this racemization would be due to the presence of soluble phosphine oxide by-product during the purification step. ${ }^{23-25}$ Conversely, enantioseparation strategy from commercially available racemate on multigram scale was executed successfully on a 1-cm diameter Chiralpak AD-H column allowing for 
the separation of $5 \mathrm{~g}$ of racemate with $6 \mathrm{~L}$ of mobile phase (hexane/EtOH, 95/5, v/v) in 1 day injection. This strategy allowed us to recover both enantiomers with high purity (ee $>99.5 \%$ ). The comparison of HPLC chromatograms obtained after enantioselective synthesis and HPLC enantioseparation gave us access to both pure enantiomers of ethyl 2,3-dibromopropionate of known absolute configurations. The preparative HPLC enantioseparation of low-price commercially available ethyl 2,3-dibromopropionate racemate could help scientists to synthesize enantiopure heterocyclic compounds, which may present potential bioactivity. Conventional preparative HPLC enantioseparation on CSP is characterized by a $50 \%$ yield constraint. Racemization of ethyl 2,3-dibromopropionate, which is a disadvantage for enantioselective synthesis, could be a complementary tool for preparative HPLC enantioseparation. Indeed, the yield of the desired enantiomer could be increased by recycling the unwanted enantiomer by racemization and performing an additional preparative HPLC enantioseparation. ${ }^{26}$

1. Agranat I, Caner H, Caldwell J. Putting chirality to work: the strategy of chiral switches. Nat Rev Drug Discov. 2002;1(10): 753-768.

2. Lorenz H, Seidel-Morgenstern A. Processes to separate enantiomers. Angew Chem Int Ed. 2014;53(5):1218-1250.

3. Coquerel G. Preferential crystallization. Top Curr Chem. 2007; 269:1-51.

4. Marckwald W, Mc. Kenzie A. Ueber eine principiell neue methode zur spaltung racemischer verbindungen in die activen bestandtheile. Ber. Dtsch. Chem Ges. 1899;32(2):2130-2136.

5. Okamoto Y, Kai T. Chiral HPLC for efficient resolution of enantiomers. Chem Soc Rev. 2008;37(12):2593-2608.

6. Francotte ER. Enantioselective chromatography as a powerful alternative for the preparation of drug enantiomers. J Chromatogr a. 2001;906(1-2):379-397.

7. Andersson S, Allenmark SG. Preparative chiral chromatographic resolution of enantiomers in drug discovery. $J$ Biochem Biophys Methods. 2002;54(1-3):11-23.
8. Sardella R, Carotti A, Manfroni G, et al. Enantioresolution, stereochemical characterization and biological activity of chiral large-conductance calcium-activated potassium channel opener. J Chromatogr a. 2014;1363:162-168.

9. Sardella R, Ianni F, Marinozzi M, Macchiarulo A, Natalini B. Laboratory-scale preparative enantioseparations of pharmaceutically relevant compounds on commercially available chiral stationary phases for HPLC. Curr Med Chem. 2017;24(8): 796-817.

10. Sharma SD, Kanwar S, Rajpoot S. Aziridines as templates: a general strategy for the stereospecific synthesis of 2-azetidinones. J. Heterocycl. Chem. 2006;43(1):11-19.

11. Fang QK, Grover P, Han Z, et al. Practical chemical and enzymatic technologies for (S)-1,4-benzodioxan2-carboxypiperizine intermediate in the synthesis of (S)doxazosin mesylate. Tetrahedron: Asymmetry. 2001;12(15): 2169-2174.

12. Butler RCM, Chapleo CB, Myers PL, Welbourn AP. Synthesis of 2-(2-imidazolinyl) substituted 2,3-dihydro-4H1,4-benzothiazine and 3,4-dihydro-2H-1,4-benzoxazines. J. Heterocycl. Chem. 1985;22(1):177-181.

13. Bourlot AS, Guillaumet G, Merour JY. A straightforward route to 4H-1,4-benzoxazine-2-carbaldehydes by swern oxidation. J. Heterocycl. Chem. 1996;33(1):191-196.

14. Tanaka H, Shibata M, Ohira K, Ito K. Total synthesis of ( \pm )-silybin, an antihepatotoxic flavonolignan. Chem Pharm Bull. 1985;33(4):1419-1423.

15. Honda $\mathrm{T}$, Terao $\mathrm{T}$, Aono $\mathrm{H}$, Ban M. Synthesis of novel 1,4-benzoxazin-3-one derivatives as inhibitors against tyrosine kinases. Bioorg Med Chem. 2009;17(2):699-708.

16. La DS, Belzile J, Bready JV, et al. Novel 2,3-dihydro1,4-benzoxazines as potent and orally bioavailable inhibitors of tumor-driven angiogenesis. $J$ Med Chem. 2008; 51(6):1695-1705.

17. Pamerla M, Reddy DRS, Rao BS, Bodipati N, Murthy YLN. Antimicrobial evaluation of 1,4-benzoxazine derivatives. Med Chem Res. 2015;24(2):611-615.

18. Mayer S, Arrault A, Guillaumet G, Merour JY. Attempted synthesis of ethyl 3,4-dihydro-2H-1,4-benzoxazine-3-carboxylate and 3-acetate derivatives. $J$ Heterocycl Chem. 2001;38(1): 221-225.

19. Touzeau F, Arrault A, Guillaumet G, et al. Synthesis and biological evaluation of new 2-(4,5-dihydro-1H-imidazol-2-yl)3,4-dihydro-2H-1,4-benzoxazine derivatives. J Med Chem. 2003; 46(10):1962-1979.

20. Blattes E, Lockhart B, Lestage P, et al. Novel 2-alkylamino1,4-benzoxazine derivatives as potent neuroprotective agents: structure-activity relationship studies. J Med Chem. 2005;18: 1282-1286.

21. Jervis PT, Cox LR. Total synthesis and proof of relative stereochemistry of (-)-Aureonitol. J Org Chem. 2008;73(19):76167624.

22. Mukaiyama T, Shiina I, Iwadare H, et al. SaitohK. Asymmetric total synthesis of Taxol. Chem. Eur. J. 1999;5:121-161.

23. Calzada JG, Hooz J. Geranyl chloride. Organic Synth. 1974; 54:63.

24. Hutchins RO, Masilamani D, Maryanoff CA. A convenient synthesis of labile optically active secondary alkyl bromides from chiral alcohols. J Org Chem. 1976;41(6):1071-1073. 
25. Canestrari D, Cioffi C, Biancofiore I, et al. Sulphide as a leaving group: highly stereoselective bromination of alkyl phenyl sulphides. Chem Sci. 2019;10(39):9042-9050.

26. Wrzosek K, Harriehausen I, Seidel-Morgenstern A. Combination of enantioselective preparative chromatography and racemization: experimental demonstration and model-based process optimization. Org Process Res Dev. 2018;22(12):17611771. 